\title{
APLICAÇÃO DE ÁCIDO BÓRICO SOBRE AS CARACTERÍSTICAS PRODUTIVAS DO REPOLHO EM DIFERENTES ÉPOCAS
}

\section{LUCIANA MARIA DA SILVA ${ }^{1}$, SCARLET DE AGUIAR BASÍLIO ${ }^{1}$, ROGÉRIO LAMIM SILVA JUNIOR ${ }^{1}$, MARIANA VIEIRA NASCIMENTO ${ }^{1}$, CLEITON GREDSON SABIN BENETT ${ }^{2}$, KATIANE SANTIAGO SILVA BENETT ${ }^{3}$}

\footnotetext{
${ }^{1,3}$ Universidade Estadual de Goiás, Ipameri-GO, Brasil, luy.mari@hotmail.com, scarletaguiar@yahoo.com.br, rogeriolamimj@gmail.com, nascimento_mariana1@hotmail.com, kasantiago@ig.com.br. ${ }^{2}$ Instituto Federal Goiano (IF Goiano), Urutaí-GO, Brasil, Cleiton.benett@ifgoiano.edu.br.
}

\begin{abstract}
RESUMO: A cultura do repolho é realizada principalmente em pequenas áreas e depende de grande mão de obra, sendo na maior parte conduzida pela agricultura familiar. O objetivo deste trabalho foi identificar a melhor época de aplicação e doses de boro para as características produtivas e qualidade de cabeças de repolho. $\mathrm{O}$ experimento foi realizado na fazenda experimental da Universidade Estadual de Goiás, Câmpus de Ipameri (UEG/Ipameri). $\mathrm{O}$ delineamento experimental utilizado foi o de blocos casualizados no esquema fatorial $2 \times 5$, sendo duas épocas de aplicação (15 e 25 dias após o transplante (DAT)) e cinco doses de boro $\left(0 ; 2,5 ; 5,0 ; 7,5\right.$ e $\left.10,0 \mathrm{~kg} \mathrm{ha}^{-1}\right)$, com quatro repetições. As parcelas foram constituídas por quatro linhas de 1,6 m dispostas no espaçamento de $0,8 \times 0,4 \mathrm{~m}$, considerando como área útil as quatro plantas centrais. Foram realizadas as seguintes avaliações: teores de boro foliar, altura e área das plantas, altura da cabeça, diâmetro da cabeça, relação da altura da cabeça e diâmetro da cabeça, número de folhas externas e internas, massa fresca e seca de folhas externas e internas, classificação do peso da cabeça, compacidade, teor de clorofila e produtividade. Nas condições em que este experimento foi conduzido a aplicação de boro aos 25 dias após o transplante proporcionou maior teor de boro foliar na cultura do repolho. A dose indicada para a máxima produção de cabeças de repolho é a de $6,8 \mathrm{~kg} \mathrm{ha}^{-1}$ de boro.
\end{abstract}

PALAVRAS-CHAVE: Brassica oleracea var. capitata L., boro, micronutrientes, produtividade

\section{APPLICATION OF BORIC ON THE CHARACTERISTICS OF PRODUCTIVE CABBAGE IN DIFFERENT TIMES}

\begin{abstract}
The cabbage crop is mainly grown in small areas and is dependent on labor, being mostly driven by family farmers. The objective of this study was to identify the best time of application and boron doses for productive characteristics and quality of cabbage heads. The experiment was conducted at the experimental farm of the State University of Goias, Campus Ipameri (UEG/Ipameri). The experimental design was a randomized complete block in a factorial $2 \times 5$, two application times (15 and 25 days after transplanting (DAT)) and five boron doses $\left(0,2.5,5.0,7,5\right.$ and $\left.10.0 \mathrm{~kg} \mathrm{ha}^{-1}\right)$, with four replications. The plots consisted of four rows of $1.6 \mathrm{~m}$ arranged in the spacing of $0.8 \times 0.4 \mathrm{~m}$, considered as useful area the four central plants. The following evaluations were performed: leaf boron levels, plants' height and area, the head height, head diameter, ratio of head height and its diameter, chlorophyll content, number of external and internal leaves, fresh and dry external and internal leaves mass, head weight classification, compactness and productivity. Under the conditions that the experiment was conducted applying boron at 25 days after transplantation
\end{abstract}


provided higher leaf boron content in cabbage culture. The stated dose to the maximum production of cabbage heads is $6.8 \mathrm{~kg} \mathrm{ha}^{-1}$ of boron.

KEYWORDS: Brassica oleracea var. capitata L., boron, micronutrients, productivity

\section{INTRODUÇÃO}

O repolho (Brassicaoleraceavar. capitataL.) é uma planta herbácea tendo grande presença na dieta alimentar das famílias brasileiras. A cultura do repolho denota um caráter social devido ao emprego de grande mão de obra, sendo cultivado essencialmente por pequenos agricultores.

Originalmente o repolho é uma hortaliça de clima temperado, bienais, independe ao fotoperíodo, sendo a temperatura o fator limitante para o desenvolvimento da planta. Seu ciclo varia de 80 a 100 dias e sua produtividade geralmente supera $50 \mathrm{t} \mathrm{ha}^{-1}$. Além de várias propriedades nutritivas; rico em vitamina $\mathrm{C}$ e sais de ferro, vitaminas $\mathrm{B} 1$, $\mathrm{B} 2$ e sais minerais (LUZ et al., 2002), é um alimento altamente versátil à indústria e à mesa, podendo ser consumido cozido, in natura, em conserva e desidratado (FILGUEIRA, 2012).

As brássicas têm grande capacidade em extração de nutrientes do solo, fornecendo nutrientes em quantidades adequadas e equilibradas, assim, é necessário, entre outros fatores, conhecer as exigências nutricionais de cada variedade botânica das brássicas (KIMOTO, 1993). Entre os micronutrientes mais exigidos pelo repolho, o boro tem grande influência sobre a produção.

O boro age na biossíntese da parede celular, auxiliando o cálcio na deposição e formação de pectatos que formam parte dessas estruturas e manutenção da integridade da membrana plasmática (SANTOS et al., 1990). Segundo Cakmaka e Romheld (1997) o boro também está relacionado ao metabolismo de RNA, carboidratos, ácido indol acético, fenol e no metabolismo do ascorbato, além da respiração com transporte de açúcares e lignificação.

A deficiência de boro na planta provoca o rápido endurecimento da parede celular, porque mesmo formando complexos com carboidratos, a disposição das micelas de celulose fica prejudicada, o que não permite o aumento normal do volume da célula (MALAVOLTA, 1980). Lenoble et al. (2000) desenvolveram a hipótese que altas concentrações de boro protegem o crescimento radicular em situações em que altos teores de alumínio normalmente seriam inibidores.

A aplicação de boro atua principalmente no crescimento e desenvolvimento do repolho, atuando nos processos metabólicos, responsáveis pelo crescimento e expansão celular, incorporação do cálcio na parede celular que auxiliam na biossíntese da mesma. Assim, as cabeças ficam compactas com a aplicação de boro resultando na qualidade final do produto (ALVARES et al., 1985).

No estado de São Paulo, Traine et al. (1996), recomendaram de 3 a $4 \mathrm{~kg} \mathrm{ha}^{-1}$ de boro para a cultura do repolho ou três aplicações foliares durante o ciclo com solução contendo $1 \mathrm{~g}$ $\mathrm{L}^{-1}$ de ácido bórico, não levando em consideração o tipo de solo. Os mesmos autores relatam que a cultura do repolho pode ser classificado como de média exigência em boro.

Carneiro et al. (1995) verificaram que as doses de boro na ausência de matéria orgânica alcançaram produção de $38,78 \mathrm{t} \mathrm{ha}^{-1}$ na cultura do repolho utilizando como fonte o bórax e Silva et al. (2012) trabalhando com cultivares e doses de boro na cultura do repolho observaram que a aplicação de boro influenciou na produtividade do repolho. Os mesmos 
autores também ressaltam a ausência de estudos enfocando a adubação boratada na cultura do repolho.

Portanto, estudos com aplicação de micronutrientes, principalmente o boro são de grande importância, visto que este exerce papel fundamental na formação das cabeças e na compacidade melhorando a qualidade e consequentemente produção mais uniforme.

Os objetivos deste trabalho foram os de identificar a melhor época de aplicação e a dose mais adequada de boro para a cultura do repolho.

\section{MATERIAL E MÉTODOS}

O experimento foi conduzido a campo nos meses de fevereiro a maio de 2014 em área experimental da Universidade Estadual de Goiás, Câmpus de Ipameri, localizada no município de Ipameri-GO com $17^{\circ} 43^{\prime}$ de latitude sul e $48^{\circ} 22^{\prime}$ de longitude oeste e altitude de 800 metros. O clima da região, segundo a classificação de Köppen é definindo como Tropical Úmido (AW), constando temperaturas elevadas com chuvas no verão e seca no inverno. $\mathrm{O}$ solo da área experimental é classificado como Latossolo Vermelho-Amarelo Distrófico (EMBRAPA, 2006).

Os atributos químicos e físicos do solo foram determinados antes da instalação do experimento, segundo metodologia proposta por Ribeiro et al. (1999), com os seguintes atributos químicos, na camada 0,0-0,20 m: $19 \mathrm{mg} \mathrm{dm}^{-3} \mathrm{de} \mathrm{P}$ (Melich); $30 \mathrm{~g} \mathrm{dm}^{-3}$ de M.O.; 5,3 de $\mathrm{pH}\left(\mathrm{CaCl}_{2}\right) ; \mathrm{K}, \mathrm{Ca}, \mathrm{Mg}$ e $\mathrm{H}+\mathrm{Al}=3,9 ; 35,0 ; 11,0$ e $28,0 \mathrm{mmol}_{\mathrm{c}} \mathrm{dm}^{-3}$, respectivamente e $64 \%$ de saturação por bases, os atributos físicos foram: argila: $390 \mathrm{~g}$, silte: $97 \mathrm{~g}$ e areia: $513 \mathrm{~g}$.

O delineamento experimental utilizado foi o de blocos casualizados no esquema fatorial $2 \times 5$, sendo duas épocas de aplicação ( 15 e 25 dias após o transplante) e cinco doses de boro $\left(0 ; 2,5 ; 5,0 ; 7,5\right.$ e $\left.10,0 \mathrm{~kg} \mathrm{ha}^{-1}\right)$, utilizando-se como fonte de boro o ácido bórico $(17 \%$ de B) com quatro repetições.

A semeadura foi realizada em bandejas de poliestireno de 128 células, preenchidas com substrato organo-mineral, mantidas em estufa telada e irrigação realizada diariamente. A variedade de repolho utilizado foi o hibrido Seminis Astrus Plus.

As mudas foram transplantadas manualmente aos 30 dias após a emergência, quando as plantas apresentavam quatro a cinco folhas definitivas. As doses de boro foram aplicadas no solo, manualmente aos 15 e 25 dias após o transplante das mudas, nas entrelinhas.

As parcelas foram constituídas por quatro linhas de 1,6 m dispostas no espaçamento de 0,8 x 0,4 m, com 16 plantas por parcela, consideradas como área útil as quatro plantas centrais. Para a adubação básica utilizou-se 20,80 e $60 \mathrm{~kg} \mathrm{ha}^{-1}$ de $\mathrm{N}, \mathrm{P}_{2} \mathrm{O}_{5}$ e $\mathrm{K}_{2} \mathrm{O}$, respectivamente. Foi realizado o controle de plantas daninhas por meio de capinas manuais, e o controle de pragas aplicando-se inseticidas a base de Deltametrina $(0,75 \mathrm{~g} / 100 \mathrm{~L}$ de água do i.a.) por meio de pulverização.

O fornecimento de água foi efetuado de acordo com as necessidades das plantas, por meio de sistema de irrigação por aspersão convencional. A adubação de cobertura foi realizada aplicando-se $140 \mathrm{~kg} \mathrm{ha}^{-1}$ de $\mathrm{N}$ parcelados aos 20 e 40 dias após o transplante, conforme Filgueira (2012).

Avaliaram-se os teores de boro foliar, onde foram coletadas dez folhas recém-maduras no início da formação da cabeça das plantas de repolho em cada parcela. O material foi seco em estufa com circulação forçada de ar com temperatura de $65^{\circ} \mathrm{C}$, por cerca de 72 horas. 
Depois de seco, o material foi moído em moinho tipo Wiley equipado com peneira de malhas com abertura de $1 \mathrm{~mm}$ e acondicionado em sacos de papel para análises, seguindo-se os métodos descritos por Malavolta et al. (1997).

Também foram avaliadas as seguintes características: altura das plantas aos 20 e 40 dias e no momento da colheita utilizando-se uma fita métrica; área da planta, mensurando-se com régua graduada o espaço ocupado pela planta, realizada aos 20 e 40 dias após o transplante e no final; altura da cabeça (AC) e diâmetro da cabeça (DC) mensurado com auxílio de uma régua em superfície plana; relação AC/DC expressa a razão entre altura da cabeça em relação ao diâmetro longitudinal da cabeça; teor de clorofila SPAD realizado através de clorofilômentro avaliando as folhas recém-maduras no início da formação da cabeça; número de folhas externas, através da contagem das folhas não comerciais; número de folhas internas, determinado por meio da retirada gradativa das folhas da cabeça e contando até a última folha; massa fresca e seca de folhas externas e internas realizadas através da pesagem da massa fresca das folhas e depois realizada a secagem em estufa de circulação de ar forçada com temperatura de $65^{\circ} \mathrm{C}$, por cerca de 72 horas, sendo posteriormente pesada para determinar a massa seca.

A classificação da massa da cabeça foi realizada conforme proposto por Vidigal et al. (2007), onde $0=<250 \mathrm{~g} ; 1=250$ a $500 \mathrm{~g} ; 2=500$ a $750 \mathrm{~g} ; 3=750 \mathrm{~g}$ a $1.000 \mathrm{~g} ; 4=1.000 \mathrm{a}$ $1.500 \mathrm{~g} ; 5=1.500$ a $2.000 \mathrm{~g}$ e $6=>2.000 \mathrm{~g}$; compacidade realizado conforme proposto por Muniz (1988) que classifica como 1 = fofa; 2 = média; 3 = firme e produtividade por hectare, realizada através da pesagem das cabeças de repolho da área útil de cada parcela, sendo os resultados posteriormente transformado para $\mathrm{kg} \mathrm{ha}^{-1}$.

A colheita foi realizada, à medida em que as cabeças de repolho atingiam o ponto tendo início aproximadamente de 90 a 100 dias após a semeadura. Assim, as avaliações seguiram a mesma ordem.

Os dados foram submetidos à análise de variância (teste F), e as médias das épocas de aplicação foram comparadas pelo teste de Tukey a 5\% de probabilidade. As doses de B foram submetidas à análise de regressão. As análises estatísticas foram processadas utilizando-se o programa de análise estatística Sanest (ZONTA et al., 1987).

\section{RESULTADOS E DISCUSSÕES}

Constatou-se que houve efeito significativo somente para o teor de boro foliar, já para as demais características avaliadas não apresentaram efeito significativo entre si em função das diferentes épocas de aplicação de boro na cultura do repolho (Tabelas 1e 2). Silva et al. (2012) trabalhando com cultivares de repolho e doses de boro, observou diferença significativa entre as cultivares quando analisou diâmetro de cabeça, altura da planta e altura da cabeça. Já Carneiro et al. (1995) quando avaliou efeito dos diferentes níveis de boro, na presença e ausência de matéria orgânica, na cultura do repolho não observou efeito significativo para a variável diâmetro de cabeça.

Para o efeito das doses de boro em relação ao número de folhas internas pode-se observar ajuste dos dados a uma regressão quadrática com ponto de máxima de $6,1 \mathrm{~kg} \mathrm{ha}^{-1} \mathrm{de}$ boro (Figura 1B). Silva et al. (2012), trabalhando com produtividade e desenvolvimento de cultivares de repolho em função das diferentes doses de boro, observaram efeitos significativos para número de folhas internas.

Resultados superiores foram constatados no teor de boro foliar com aplicação aos 25 dias após o transplante (DAT) em relação à aplicação de boro aos 15 DAT (Tabela 2). 
Tabela 1. Valores da altura da planta aos 20 dias após o transplante (ALT 20), altura da planta aos 40 dias após o transplante (ALT 40), altura final da planta (ALT), área da planta aos 20 dias após o transplante (AP 20), área da planta aos 40 dias após o transplante (AP 40), área final (AP), altura da cabeça (AC), diâmetro da cabeça (DC), relação da altura e diâmetro da cabeça (AC/DC), número de folhas externas (NFE) e número de folhas internas (NFI) em função de diferentes épocas de aplicação de boro na cultura do repolho. Ipameri-GO, 2014.

\begin{tabular}{|c|c|c|c|c|c|c|}
\hline Tratamentos & ALT 20 & ALT 40 & ALT & AP 20 & AP 40 & AP \\
\hline Aplicação de boro & \multicolumn{3}{|c|}{----------- cm ----------- } & \multicolumn{3}{|c|}{---------- $\mathrm{cm}^{2}$---------- } \\
\hline $15 \mathrm{DAT}^{*}$ & $11,60 \mathrm{a}$ & $20,60 \mathrm{a}$ & $29,73 \mathrm{a}$ & $334,20 \mathrm{a}$ & $1029,86 \mathrm{a}$ & $2436 \mathrm{a}$ \\
\hline $25 \mathrm{DAT}$ & $11,73 \mathrm{a}$ & $20,20 \mathrm{a}$ & $30,40 \mathrm{a}$ & $377,80 \mathrm{a}$ & $1163,80 \mathrm{a}$ & $2571 \mathrm{a}$ \\
\hline $\mathrm{CV}(\%)$ & 12,22 & 9,11 & 8,53 & 20,83 & 18,88 & 13,50 \\
\hline Tratamentos & & & $\mathrm{C}$ & & & \\
\hline Aplicação de boro & \multicolumn{3}{|c|}{------ cm ------ } & AC/DC & NFE & NFI \\
\hline $15 \mathrm{DAT}^{*}$ & \multirow{2}{*}{\multicolumn{2}{|c|}{$\begin{array}{l}12,73 \mathrm{a} \\
12,40 \mathrm{a}\end{array}$}} & $15,93 \mathrm{a}$ & $0,73 \mathrm{a}$ & $12,60 \mathrm{a}$ & $37,80 \mathrm{a}$ \\
\hline $25 \mathrm{DAT}$ & & & \multirow{2}{*}{$\frac{6,00 \mathrm{a}}{8,54}$} & $0,71 \mathrm{a}$ & $12,53 \mathrm{a}$ & $37,40 \mathrm{a}$ \\
\hline $\mathrm{CV}(\%)$ & \multicolumn{2}{|c|}{7,91} & & 16,58 & 10,08 & 5,66 \\
\hline
\end{tabular}

Médias seguidas de mesma letra na coluna, para cada fator estudado, não diferem entre si pelo teste de Tukey a 5\% de probabilidade. * DAT: Dias após o transplante.

Quando avaliadas as doses de boro na cultura do repolho, observou-se efeito significativo para diâmetro de cabeça e número de folhas internas (Figura 1). Os valores do diâmetro da cabeça (Figura 1A) se ajustaram a uma regressão quadrática com ponto de máximo de $6,8 \mathrm{~kg} \mathrm{ha}^{-1}$ de boro. Esses resultados não corroboram com os resultados encontrados por Silva et al. (2012), que observaram ajuste dos dados a uma regressão linear crescente.
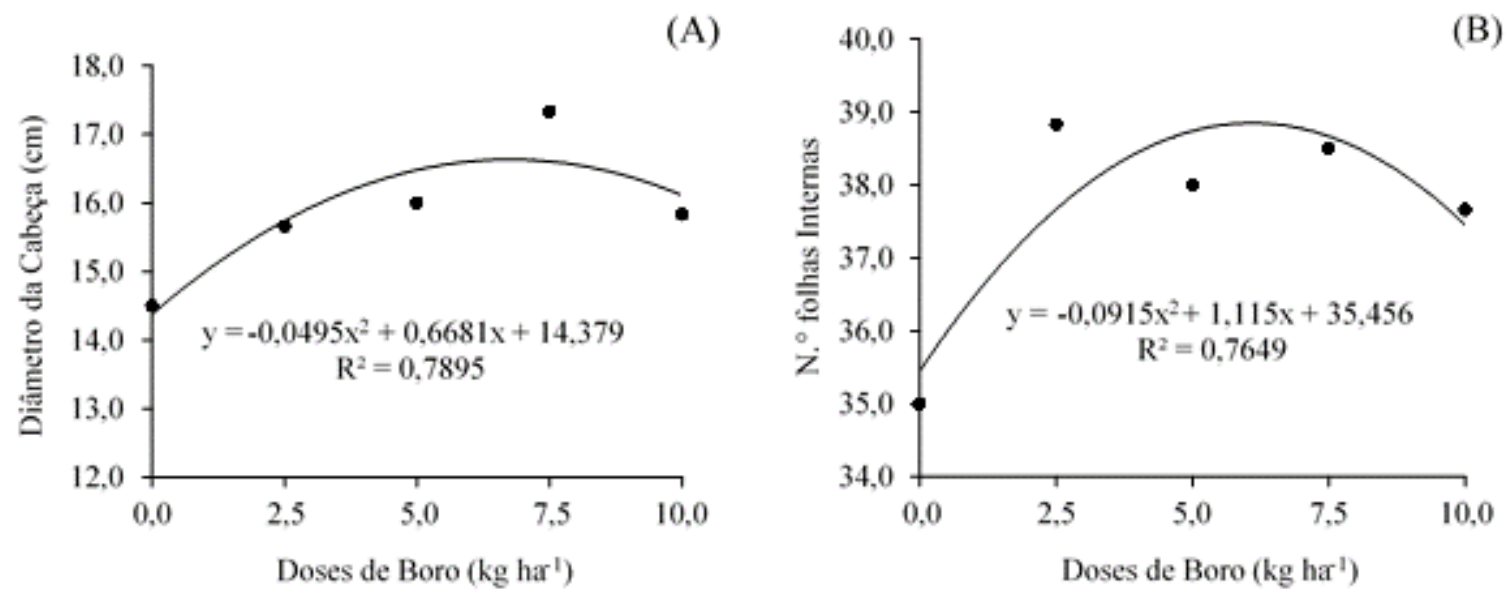

Figura 1. Valores médios do diâmetro da cabeça (A) e número de folhas internas (B) em função de doses de boro na cultura do repolho. Ipameri-GO, 2014.

Bergamim et al. (2005) ao avaliarem a produção de repolho em função da aplicação de boro associada a adubo orgânico observaram variação do teor de boro na folha envoltória entre 23-44 mg kg-1 . Constataram que estes valores estão abaixo do recomendado por Trani et al. (1996), porém as folhas não apresentaram sintoma visual de deficiência. 
Tabela 2. Valores médios do teor de boro foliar (TBF), matéria fresca de folhas externa (MFE), matéria fresca de folhas internas (MFI), matéria seca de folhas externas (MSE), matéria seca de folhas internas (MSI), classificação da massa da cabeça (CLASS), compacidade (COMP), teor de clorofila SPAD (CLOR) e produtividade por hectare (PROD) sobre diferentes épocas de aplicação de boro na cultura do repolho. Ipameri-GO, 2014.

\begin{tabular}{|c|c|c|c|c|c|}
\hline Tratamentos & $\mathrm{TBF}$ & MFE & MFI & MSE & MSI \\
\hline Aplicação de boro & $\mathrm{mg} \mathrm{kg}^{-1}$ & \multicolumn{4}{|c|}{------------------- g planta' ${ }^{-1}$------------------ } \\
\hline $15 \mathrm{DAT}^{*}$ & $35,80 \mathrm{~b}$ & $100,12 \mathrm{a}$ & $215,40 \mathrm{a}$ & $8,92 \mathrm{a}$ & $9,41 \mathrm{a}$ \\
\hline $25 \mathrm{DAT}$ & $42,60 \mathrm{a}$ & $107,45 \mathrm{a}$ & $222,51 \mathrm{a}$ & $10,35 \mathrm{a}$ & $9,55 \mathrm{a}$ \\
\hline $\mathrm{CV}(\%)$ & 13,54 & 13,13 & 25,40 & 19,91 & 13,81 \\
\hline Tratamentos & \multirow{2}{*}{\multicolumn{2}{|c|}{ CLASS }} & \multirow{2}{*}{ COMP } & \multirow{2}{*}{ CLOR } & PROD \\
\hline Aplicação de boro & & & & & $\mathrm{kg} \mathrm{ha}^{-1}$ \\
\hline $15 \mathrm{DAT}^{*}$ & & & 2,46 a & 39,59 a & $27290 \mathrm{a}$ \\
\hline 25 DAT & & & $2,40 \mathrm{a}$ & $38,35 \mathrm{a}$ & $29008 \mathrm{a}$ \\
\hline $\mathrm{CV}(\%)$ & & & 20,47 & 6,57 & 15,65 \\
\hline
\end{tabular}

Avaliadas as doses de boro na cultura do repolho observou-se efeito significativo para teor de boro foliar, classificação de cabeça, compacidade, teor de clorofila e produtividade por hectare (Figura 2). Os teores médios de boro foliar se ajustaram a regressão linear positiva (Figura 2A), sendo estes valores inferiores aos encontrados por Silva et al. (2012) e dentro do recomendado por Trani et al. (1996), que afirmam que para um bom desenvolvimento os teores de boro foliar devem estar situados na faixa de $25-75 \mathrm{mg} \mathrm{kg}^{-1}$.

Para a classificação do peso da cabeça em função das doses de boro, observou-se que os dados se ajustaram a uma regressão quadrática (Figura 2B), com ponto de máximo de 7,0 $\mathrm{kg} \mathrm{ha}^{-1}$ de boro. Este resultado se assemelha ao encontrado por Silva et al. (2012).

Quando se determinou a compacidade (Figura 2C), observou-se que os dados também se ajustaram a uma regressão quadrática com ponto de máximo de $7,8 \mathrm{~kg} \mathrm{ha}^{-1}$ de boro. Para Pizetta et al. (2005) quando utilizaram adição de 6 e $8 \mathrm{~kg} \mathrm{ha}^{-1}$ de B verificaram menor número de cabeças na classe 1 e aumentaram na classe 2, atingindo $97 \%$ de cabeças nesta última classe. O aumento de cabeças na classe 2 , com $8 \mathrm{~kg} \mathrm{ha}^{-1}$, foi de $21 \%$ em relação ao tratamento sem B.

Para teor de clorofila (Figura 2D) observou-se que os dados se ajustaram a uma regressão quadrática com ponto de máximo de $6,3 \mathrm{~kg} \mathrm{ha}^{-1}$ de boro. Esse fato pode ser explicado devido à participação do boro no metabolismo do nitrogênio e na atividade de hormônios, além de ser essencial na translocação de açúcares e no metabolismo de carboidratos (DECHEN; NACHTIGALL, 2007).

Quando se avaliou produtividade por hectare em função das diferentes doses de boro (Figura 2E) observou-se que os dados se ajustam a uma regressão quadrática com ponto de máxima de $6,8 \mathrm{~kg} \mathrm{ha}^{-1}$ de boro. Estes resultados se assemelham com os encontrados por Silva et al. (2012), que ao analisarem produtividade e desenvolvimento de cultivares de repolho em função das doses de boro, observaram ajuste dos dados a uma regressão quadrática. Estes resultados divergem do encontrado por Bergamim et al. (2005), que verificaram na produção 
de repolho ajuste a uma regressão linear em função da aplicação de doses de boro que foram de 0 a $8 \mathrm{~kg} \mathrm{ha}^{-1}$.
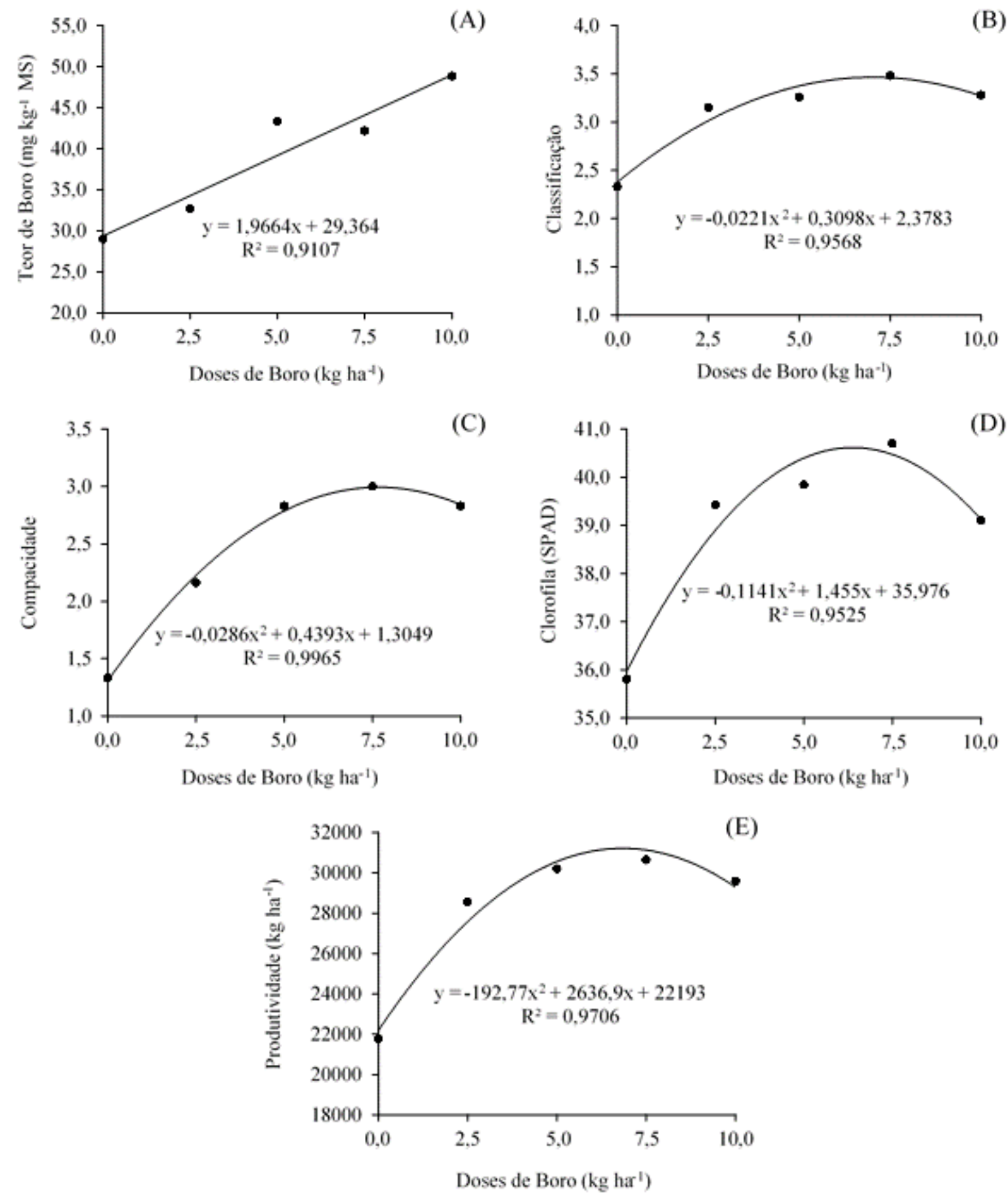

Figura 2. Valores médios do teor de boro foliar (A), classificação de cabeças (B), compacidade $(\mathrm{C})$, teor de clorofila (D) e produtividade por hectare (E) em função de doses de boro na cultura do repolho. Ipameri-GO, 2014.

Carneiro et al (1995), aplicando doses de boro na ausência de matéria orgânica, observaram que a produção máxima $\left(38,78 \mathrm{t} \mathrm{ha}^{-1}\right)$ seria obtida com a dosagem $101 \mathrm{~kg} \mathrm{ha}^{-1} \mathrm{de}$ bórax, no entento a aplicação de $20 \mathrm{~kg}^{-1}$ garantiu 96,9\% do rendimento máximo e concluíram que aplicações acima desta dosagem são desnecessárias. 


\section{CONCLUSÕES}

Nas condições que esse experimento foi conduzido, a aplicação de boro aos 25 dias após o transplante proporcionou maior teor de boro foliar na cultura do repolho. boro.

A dose indicada para a máxima produção de cabeças de repolho é a de $6,8 \mathrm{~kg} \mathrm{ha}^{-1} \mathrm{de}$

\section{REFERÊNCIAS BIBLIOGRÁFICAS}

Álvares, M. C.; OliveirA, S. A; MATTOS, J. K. A.; MESQUiTA Filho, M. V. Resposta de repolho à adubação com bórax. Horticultura brasileira, Brasília-DF, v. 3, n. 2, p. 18-21, 1985.

BERGAMIN, L.G.; CRUZ, M.C.P.; FERREIRA, M.E.; BARBOSA, J.C. Produção de repolho em função da aplicação de boro associada à adubo orgânico. Horticultura Brasileira, Brasília-DF, v. 23, n. 2, p. 311-315, 2005.

CAKMAK, I.; RÖMHELD, V. Boron deficiency-induced impairments of celular functions in plants. Plant and Soil, Dordrecht, v. 193, n. 1/2, p. 71-83, 1997.

CARNEIRO, I. F.; ALMEIDA NETO, J. X.; NAVES, R. V.; CHAVES, L. J. Efeitos de diferentes níveis de boro, na presença e ausência de matéria orgânica, na cultura do repolho. Escola de agronomia e veterinária, Goiânia-GO, v. 25, n. 1, p. 1-11, 1995.

DECHEN, A. R.; NACHTIGALL, G. R. Elementos requeridos à nutrição de plantas. In: NOVAIS, R. F.; ALVAREZ, V. V. H.; BARROS, N. F.; FONTES, R. L. F.; CANTARUTTI, R. B.; NEVES, J. C. L. (eds). Fertilidade do Solo. Viçosa-MG: SBCS/UFV, 2007. p. 92-132. EMBRAPA. EMPRESA BRASILEIRA DE PESQUISA AGROPECUÁRIA. Centro Nacional de Pesquisa de Solos. Sistema brasileiro de classificação de solos. Rio de JaneiroRJ: Embrapa, 2006. 306 p.

FILGUEIRA, F. A. R. Agrotecnologia moderna na produção e comercialização de hortaliças. Novo manual de olericultura. 3. ed. Viçosa-MG: UFV, 2012. 421 p.

KIMOTO, T. Nutrição e adubação de repolho, couve-flor e brócolo. In: FERREIRA, M. E.; CASTELLANE, P. D.; CRUZ, M. P. C. Nutrição e adubação de hortaliças. Piracicaba-SP: POTAFOS, 1993. 480 p.

LENOBLE, M. E.; BLEVINS, D. G.; MILLES, R. J. Boro extra mantém crescimento radicular sob condições de alumino tóxico. Informações agronômicas, Piracicaba-SP, n. 92, p. 3-4, 2000.

LUZ, F. J. F.; SABOYA, R. C. C.; PEREIRA, P. R. V. S. O cultivo do repolho em Roraima. Boa Vista-RO: Embrapa Roraima, 2002. 17 p. (Circular técnica, 7).

MALAVOLTA, E. Elementos de Nutrição Mineral de Plantas. São Paulo-SP: Agronômica Ceres, 1980. $251 \mathrm{p}$.

MALAVOLTA, E.; VITTI, C. G.; OLIVEIRA, S. A. Avaliação do estudo nutricional das plantas: princípios e aplicações. Piracicaba-SP: Potafós, 1997. 319 p.

MUNIZ, J. O. L. Avaliação de cultivares e híbridos de repolho. Horticultura Brasileira, Brasília-DF, v. 6, n. 1, p. 14-15, 1988. 
PIZETTA, L. C.; FERREIRA, M. E.; CRUZ, M. C. P.; BARBOSA, J. C. Resposta de brócolis, couve-flor e repolho à adubação com boro em solo arenoso. Horticultura Brasileira, Brasília-DF, v. 23, n. 1, p. 51-56, 2005.

RIBEIRO, A. C.; GUIMARÃES, P. T. G.; ALVAREZ, V. H. Recomendações para o uso de corretivos e fertilizantes em Minas Gerais $-5^{\text {a }}$ aproximação. Viçosa-MG: UFV, 1999. 359 p.

SANTOS, I.S.; BARBEADO, C.J.; PIPITAI, R.; FERREIRA, S.M.; NAKAGAWA, J. Estudo da relação Ca x B na cultura do pimentão. Horticultura brasileira, Brasília-DF, v. 8, n. 2, p. 19-23, 1990.

SILVA, K. S.; SANTOS, E. C. M.; BENETT, C. G. S.; LARANJEIRA, L. T.; EBERHARDT NETO, E.; COSTA, E. Produtividade e desenvolvimento de cultivares de repolho em função de doses de boro. Horticultura Brasileira, Brasília-DF, v. 30, n.3, p. 520-525, 2012.

TRANI, P. E.; PASSOS, F. A.; AZEVEDO, J. A.; TAVARES, M. Brócolos, couve-flor e repolho. In: RAIJ, B. VAN; CANTARELLA, H.; QUAGGIO, J. A.; FURLANI, A. M. C. (Ed.) Recomendações de adubação e calagem para o Estado de São Paulo. Campinas-SP: Instituto Agronômico/Fundação IAC, 1996, p. 175.

VIDIGAL, S. M.; PEREIRA, P. R. G.; PEDROSA, M. W. Repolho. In: PAULA JÚNIOR, T. J. de; VENZON, M. (Coord). 101 Culturas: manual de tecnologias agrícolas. Belo Horizonte-MG: EPAMIG, 2007. p. 655-674.

ZONTA, E. P.; MACHADO, A. A.; SILVEIRA JÚNIOR, P. Sistema de análise estatística para microcomputadores: Manual de utilização. 2. ed. Pelotas-RS: UFPEL, 1987. 